\title{
Distributional Issues in Natural Capital Accounting: An Application to Land Ownership and Ecosystem Services in Scotland
}

\author{
Giles Atkinson $^{1} \cdot$ Paola Ovando ${ }^{2,3}$
}

Accepted: 2 October 2021 / Published online: 28 December 2021

(c) The Author(s) 2021

\begin{abstract}
Accounting for ecosystems is increasingly central to natural capital accounting. What is missing from this, however, is an answer to questions about how natural capital is distributed. That is, who consumes ecosystem services and who owns or manages the underlying asset(s) that give rise to ecosystem services. In this paper, we examine the significance of the ownership of land on which ecosystem assets (or ecosystem types) is located in the context of natural capital accounting. We illustrate this in an empirical application to two ecosystem services and a range of ecosystem types and land ownership in Scotland, a context in which land reform debates are longstanding. Our results indicate the relative importance of private land in ecosystem service supply, rather than land held by the public sector. We find relative concentration of ownership for land providing comparatively high amounts of carbon sequestration. For air pollution removal, however, the role of smaller to medium sized, mostly privately owned, land holdings closer to urban settlements becomes more prominent. The contributions in this paper, we argue, represent important first steps in anticipating distributional impacts of natural capital (and related) policy in natural capital accounts as well as connecting these frameworks to broader concerns about wealth disparities across and within countries.
\end{abstract}

Keywords Distribution · Ecosystem services · Equity $\cdot$ Natural capital accounting · Landownership

JEL Classification Q56·Q57

Giles Atkinson

mailg.atkinson@1se.ac.uk

1 Department of Geography and Environment and Grantham Research Institute for Climate Change and Environment, London School of Economics and Political Science, Houghton Street, London WC2A 2AE, UK

2 Present Address: Institute of Public Goods and Policies, Spanish National Research Council (CSIC), Madrid, Spain

3 Social, Economic and Geographical Sciences Group (SEGS), The James Hutton Institute, Aberdeen, Scotland, UK 


\section{Introduction}

Natural capital accounting (NCA) describes a body of statistical work that seeks to construct better metrics of nature for policy. While there is no hard and fast definition of what NCA is, at its core is an emphasis on measuring flows-typically called 'ecosystem services'-as well as the underlying 'natural capital' stocks giving rise to these outputs. A connection to national accounting principles and practice is also a prominent theme (e.g. Obst and Vardon 2014; Obst et al. 2016).

A core of this work has focused on ecosystems. ${ }^{1}$ Barbier (2011) defines natural capital in this context as the physical area of a recognizable ecological landscape. For practical purposes this is often interpreted as referring to broad habitats, more commonly called ecosystem types. A comprehensive framework for ecosystem accounting can be found in UN (2021). This sets out ecosystem accounts, as a component of the United Nations System of Environmental and Economic Accounts (henceforth, SEEA-EA), which has been adopted as an international statistical standard and is thus focal to on-going and planned official work within countries. ${ }^{2}$

Indeed, a growing number of countries have set statistical processes for ecosystem accounting in motion (see, for a review and discussion, Hein et al. 2020a). It is such efforts that we describe as NCA in this paper. The promise of these natural capital accounts is that they might provide important information about the value of natural capital and can be used to support public policy and land-use management decisions (see, for example, Helm, 2019). Increasingly NCA has considered the degree of spatial detail that is needed to make good on this promise (e.g. Bateman et al. 2011; Hein et al. 2016,2020b; Ovando et al. 2017; Campos et al. 2019; McVittie and Glenk, 2019; Faccioli et al. 2019; Grunewald et al. 2020).

In the current paper we focus on a different spatial dimension that has so far been neglected in NCA: how natural capital is distributed amongst economic actors, i.e. people and organizations. While the SEEA-EA anticipates that adding distributional layers on land management and ownership characteristics might be critical for assessing policy effectiveness (UN 2021, p. 59), we argue that it is also likely to be important for what it reveals about how natural wealth is distributed and how distributional effects of environmental policies might be anticipated using NCA.

Our contribution, in this paper, is to demonstrate the relevance of distributional issues with regards to accounting for ecosystem assets and services. To the best of our knowledge, this is the first paper to make this connection to NCA. We illustrate this further using an empirical application to Scotland, although our approach has broader applicability to NCA elsewhere as well. In particular, we account for the use and supply distribution of two ecosystem services (climate change regulation through carbon sequestration and air pollution removal) across private and publicly owned land on which natural capital is located. Our findings indicate the relative importance of private land in the supply of these ecosystem services. However, how natural capital value is distributed by relative size of privately owned landholding depends on the particular ecosystem service examined.

\footnotetext{
1 Defined as a "... biological community together with the abiotic environment in which it is set." (Begon et al. 2006, p 499).

2 Specifically, Chapters 1-7 of UN (2021) have been adopted as an international standard while Chapters 8-11 have the status of internationally recognized statistical principles for valuing ecosystem services and assets.
} 
Table 1 Aggregate Ecosystem Services in Scotland and the United Kingdom in 2016. Source: Own elaboration based on ONS (2019, 2020a, 2020b). Prices deflated to 2016, from original ONS data

\begin{tabular}{|c|c|c|c|c|}
\hline & \multicolumn{2}{|c|}{ Total (£ millions) } & \multicolumn{2}{|c|}{ Per capita $(£)$} \\
\hline & Scotland & UK & Scotland & UK \\
\hline Provisioning services & 2142 & 9874 & 397 & 151 \\
\hline $\begin{array}{l}\text { Regulating and mainte- } \\
\text { nance services }\end{array}$ & 794 & 3270 & 147 & 50 \\
\hline \multicolumn{5}{|l|}{ of which: } \\
\hline - Carbon sequestration & 721 & 1760 & 134 & 27 \\
\hline - Air pollution removal & 72 & 1241 & 13 & 19 \\
\hline Cultural services & 779 & 11,156 & 144 & 170 \\
\hline Total & 3715 & 24,300 & 688 & 370 \\
\hline
\end{tabular}

Population used to calculate per capita estimates refers to mid-year estimates. Provisioning service includes: agricultural biomass, fish capture, timber, water abstraction, minerals, fossil fuels, and, renewable energy; Regulating and maintenance service includes: carbon sequestration, air pollution removal, noise mitigation, and urban cooling; Cultural service includes recreation and amenity

This rest of this paper is organized as follows. Section 2 sets out the rationale for interest in the distribution of natural capital as well as the accounting framework we rely on. Section 3 describes methods and data for our application. Section 4 outlines our main findings. Section 5 discusses and concludes.

\section{Distributional Issues and Natural Capital Accounting: Concepts and Framework}

\subsection{Natural Capital Through a Distributional Lens}

Our starting point in arguing for the significance of distributional issues in NCA is that if natural capital is a critically valuable component of national wealth —as, for example, Helm (2019) compellingly argues - then knowing how that value is distributed is surely relevant as well. As an illustration, Table 1 provides an example of ongoing work by the UK Office for National Statistics (ONS) to measure the aggregate value of natural capital in the United Kingdom and Scotland specifically (ONS 2019, 2020a). The data illustrated here refer to the value of flows of ecosystem services (produced by natural capital) in the year 2016 in current GBP (£) in total and in per capita terms. The Table also identifies two regulating and maintenance services — carbon sequestration and air pollution removalthat we explore later in the current paper. While a number of questions might arise from such estimates, the one that concerns us here is how this value is distributed and how NCA might be used to throw light on such matters.

Typically, value in NCA is understood in terms of the value to users: that is, it is conceived as what ecosystem services are ultimately worth to the people who consume them. Distributional issues, however, characterize this process of value creation at various points. For example, in NCA studies, it is already typical to distinguish private from public (use) value (with the latter corresponding to the provision of public goods and positive externalities, as conventionally defined) (e.g., Cornes and Sandler 1996; OECD 2015). Outside of NCA, studies such as Mullin et al. (2018) have sought to assess how ecosystem services, 
providing public value, are consumed across different socioeconomic groups. This might have a number of implications. For example, Meya (2020) shows how the distribution of use of ecosystem services, by income group, can affect the total value of that good. Perhaps a more general point is that many public ecosystem services map onto a host of established environmental justice concerns including local air quality and global climate change as well as access to "greenspace" (see, for example, Walker 2012 and, more recently, Riley and Gardiner 2020 for an empirical application in the context of urban trees in the US).

Elsewhere in the value creation process distributional issues may also arise in the supply of ecosystem services. These services arise from processes of natural production, with natural capital assets as production factors. But these ecosystem assets will be located on land in some way, and natural production and ecosystem service supply will be militated by how that land is managed by a range of different economic actors. ${ }^{3}$ In many instances, this land will have a formal owner. But in other instances it will not, as in the case of land which is open access or where property rights are incomplete or more informal (Bromley 1991). Where land is formally owned, the legal owner might be in the private sector or the public sector. This, in turn, might refer to a number of organizations including general government or state-owned enterprises (in the case of the public sector) as well as private businesses and charitable organizations (in the case of the private sector). In addition, legal owners might sub-contract land to other organizations who, as tenants, then take on responsibility for managing that land (a point we return to below: see Sect. 2.2).

Notably, Hanley et al. (2012) highlight the importance of privately owned land for ecosystems and species habitat services across a number of countries. Brown and Shogren (1998) report a clear preponderance of species listed in the US Endangered Species Act being dependent on private land in that country. ${ }^{4}$ In such instances, a further distinction might be the size of landholdings that these private organizations either own or make use of. In the context of agricultural land, Europe provides an illustration of what we mean by this. For instance, a small share (3.3\%) of landholders control more than half $(52.7 \%)$ of utilized area land (UAA) in the EU-28 on average (Eurostat 2020). ${ }^{5}$ Of course, this average disguises some considerable variation. Nevertheless, in 2016, in at least 15 Member States the very largest farm holdings controlled half or more of this utilized agricultural land. This includes founding Member States (such as France and Germany) as well as more recent entrants (such as the Czech Republic and Hungary). ${ }^{6}$ Bauluz et al. (2020) allows such insights from Europe to be further contextualized. Their findings for Asia, Africa and Latin America also highlight the relevance of land inequality globally, albeit with variation

\footnotetext{
3 Where, for current purposes, this might refer to terrestrial or aquatic spatial areas.

4 Moreover, one-third of these listed species were exclusively dependent on private land (Brown and Shogren, 1998).

5 The definition of an agricultural landholding in Eurostat is: "a single unit, both technically and economically, operating under a single management and which undertakes economic activities in agriculture within the economic territory of the European Union, either as its primary or secondary activity". https:// ec.europa.eu/eurostat/statistics-explained/index.php/Glossary:Agricultural_holding [Last accessed: May 17, $2021]$.

${ }^{6}$ In the case of these newer accession states, a proximate cause of larger concentrations of land holdings is the privatization and land restitution processes of formerly state-owned land (Kay et al. 2015), but also land consolidation aimed at forming larger land holding in areas with fragmented land ownership (Pašakarnis and Maliene 2010).

7 Moreover, in the Czech Republic and Slovakia, findings in Bański (2017) indicate the coincidence of relatively small holdings of legally owned land which is leased as part of larger land parcels to relatively bigger commercial farming enterprises.
} 
in terms of regions and countries as well as the inequality metric used (e.g. land area vs. land value $)^{8}$

In the case of agricultural production, there are particular debates about how a skewed distribution of landholdings matters (e.g. Kay et al. 2015). The implications of unequal land distribution for ecosystem service supply requires separate consideration. Some contributions, for example, have couched this in terms of the possible relationship between the size of landholdings and the extent of natural production which takes place on that land. Helm (2019) speculates that smaller (mixed) farms might be associated with better management of natural capital and Guiomar et al. (2018) note evidence of the role of smaller farms in promoting related concerns such as ecological diversity and resilience. Benra and Nahuelhual (2019), however, explores the relationship between size of farm holdings (in terms of land area) and extent of forest ecosystems on those holdings in Chile, with results that suggest larger properties are substantially more significant for regulating and maintenance services as well as cultural services. ${ }^{9}$

For the supply of public ecosystem services, perhaps what ultimately matters is how policy interventions better align the behaviour of landholders-regardless of the size of their landholdings-with the public good. In this sense, policy choices-by constraining (or otherwise) land management decisions - might reflect judgements about property rights and entitlements to particular goods and services (Bromley 1991). Pannell (2008), for example, discusses a broad portfolio of policy options in terms of their suitability given the mix of private net benefits (to landholders) and public net benefits (to broader society) that will be generated, while Hanley et al. (2012) and Teytelboym (2019) reflect on policy options which (respectively) focus specifically on economic incentives and natural capital market creation. Of course, any of these policies will have distributional consequences to a greater or lesser extent. In the case of regulations, for example, these impose obligations on landholders. This might be construed in terms of requiring that those who manage ecosystem assets on their landholdings to be responsible for redress arising from degradation of these assets; broadly analogous perhaps to the polluter-pays-principle in environmental policy. Such obligations, in turn, impose opportunity costs on landholders (Brown and Shogren 1998).

Hanley et al. (2012), however, emphasize a reluctance (for political and practical as well as economic reasons) to compel landholders to behave in this way. Rather a policy norm, in many (although not all) countries, tends to lean on voluntary commitments perhaps with participation being rewarded via explicit payments. This is significant not only for what it says about (implied) property rights. Such interventions endow landholders with financialized claims (to use the terminology of Naidu 2017) on the stream of ecosystem services they might maintain and enhance. Whether this might disproportionately benefit larger landholders is another matter although evidence from evaluations of payment for ecosystem service schemes appears to be strongly suggestive of this possibility (Pascual et al. 2014; Lansing 2014; Benra and Nahuelhual 2019).

Moreover, concerns about distributional outcomes privileging larger landholders might not be unconnected to procedural justice. Bromley and Hodge (1990), for example, describe this in terms of a tussle among such private actors to influence the way in which public policy (re)defines property rights, or otherwise. Moreover, this could relate

\footnotetext{
${ }^{8}$ In addition, these authors consider how the picture of inequality in land is further affected by numbers of landless people within and across countries.

9 Specifically, water regulation and recreational opportunities respectively.
} 
to political influence that comes with land-owning, in particular. Contributions by Cahill (2001), Wightman (1996) and most recently Shrubsole (2019) have sought to map land ownership for the UK, Scotland, and England respectively with these considerations broadly in mind. Furthermore, as Christophers (2018) notes, the underlying basis for such influence evolves over time with ecosystem assets-located on land which they own - and the public services these assets give rise to perhaps emerging as a contemporary manifestation of this.

For example, institutional arrangements governing land management and ownership are likely to have implications for how distinct stakeholder groups are recognized or heard in decision-making processes that shape the development of, and access to land (Wightman 1996; Walker 2012). There are parallels here with concerns articulated in the broader debate about wealth inequality and its measurement (e.g. Boushey et al. 2017; Piketty et al. 2018; Barbier 2018). In the words of DeLong et al. (2017) ownership of substantial wealth provides: "... a megaphone with which to amplify the voices of the wealthy both in the corridors of power and in the public sphere" (p3).

\subsection{Accounting Framework}

Our empirical focus is on the physical and monetary flow of ecosystem services, as well as ecosystem extent, disaggregated within NCA to look at distributional issues. As discussed in Sect. 2.1, part of our motivation for this is interest in the potential distributional implications of natural capital policy. One way of exploring these concerns might be to use NCA as an input to forward-looking policy modelling and distributional analysis. Our focus here, however, is on integrating this distributional detail within the NCA itself. Our objective in this respect is two-fold. First, we seek to show how NCA might be utilized to throw light on distributional concerns. Secondly, and relatedly, this demonstrably provides a distributional baseline against which changes arising from a policy analysis of specific interventions might at least be anticipated and evaluated further perhaps at a later stage.

Bright et al. (2019) rehearses a NCA framework that has informed UK statistical work underpinning the application that we elaborate from Sect. 3 onwards. This starts by identifying the physical extent of a natural capital asset. These ecosystem extent accounts typically characterize the spatial area of ecosystem asset, in terms of ecosystem types (e.g. woodland, semi-natural grassland, farmland and so on). Beyond the extent account, ecosystem condition and quantification of ecosystem service flows are of particular interest for natural capital accounting. Ecosystem condition is usually referred to as the quality of an ecosystem in terms of ifs biotic and abiotic characteristics (UN 2021). And both extent and condition of ecosystems directly affect their capacity to provide services (La Notte et al. 2019). Ecosystem service flow accounts then record those services arising from the ecosystem asset. These flows initially are accounted for in terms of physical units: e.g. tonnes of carbon sequestered, pollutants absorbed (and associated number of adverse health outcomes averted) and so on. Monetary accounts may follow to record the value of these flows, assuming a suitable price exists to assign to an ecosystem service.

In the current paper, our focus is on ecosystem service flows and ecosystem extent: key constituents of NCA, but not a full coverage. Notably, this absents ecosystem condition: accounts of which take stock of the state of, and trends in, ecosystems in combination perhaps with indicators of the pressures on these systems. As noted by Mace (2019), this is not only important for describing how ecosystem services are produced but it is also crucial for understanding how changes in the underlying ecosystem assets might affect future 
(a) Conventional supply and use table for ecosystem services

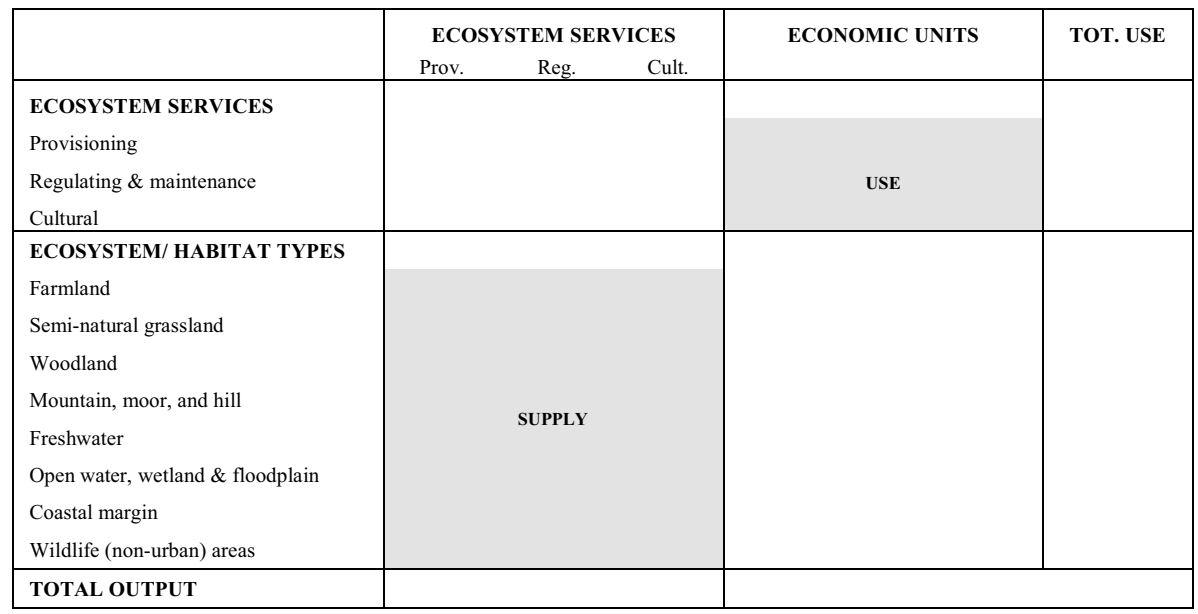

(b) Extension to landholders

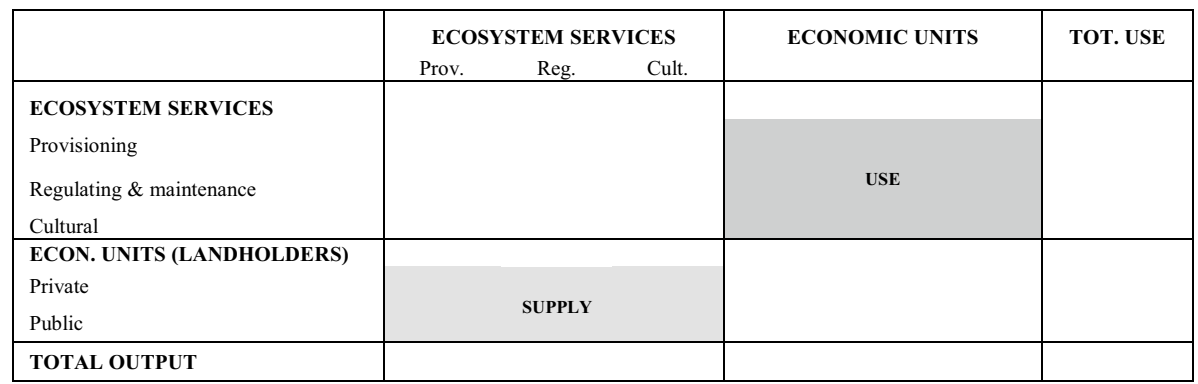

Fig. 1 Illustrative supply and use tables for ecosystem services. Source: Adapted from Vallecillo et al. (2019); ONS (2020a)

services. For example, Hein et al. (2016) examine how accounting for ecosystem capacity and condition might enable judgements about whether current ecosystem service provision can be sustained. Hein et al. (2020b) provide a general discussion and application to the Netherlands, while Grunewald et al. (2020) examines ecosystems extent and condition accounts in Germany using land-use and ecosystem data that is compatible with EU-wide approaches. Challenges remain, not least in practical interpretation of sustainability in ecosystem service supply in the light of what is revealed by accounts of ecosystem condition and capacity (see, for example, Hein et al. 2016; La Notte et al. 2017, 2019). While our emphasis abstracts from these important debates, by focusing only on current ecosystem services, it is nevertheless a critical first step in elaborating distributional issues in NCA. Moreover, the distributional analysis that we illustrate could be extended and applied to these other NCA approaches and frameworks.

A natural development of ecosystem service flow accounts is based on a Supply and Use Table (SUT) and it is this what we use as the basis of our distributional analysis in what follows. In national accounts, a SUT refers to the resources produced-economic goods and services - and their use by economic units (i.e. institutional units reflecting the various 
sectors of the economy) (see, UN 2009, 2018). In the case of NCA, the emphasis of a SUT is the flow of ecosystem services: from where these are supplied and how these are used.

This is illustrated in panel (a) of Fig. 1, where ecosystem services might be described in physical or monetary terms. Ecosystem service supply is described by ecosystem types/ broad habitat categories (i.e. natural capital, as defined). Ecosystem service use indicates how ecosystem services are used by economic units as intermediate inputs to businesses (e.g. soil fertility) and final use by households (e.g. air pollution removal and carbon sequestration) and so on. ${ }^{10}$

This format provides the basis for developing important detail for decision-makers with regards to ecosystem service provision and which elements of the economic system are directly dependent on these flows, and to what extent. ${ }^{11}$ Nevertheless, this standard approach remains silent on distributional issues such as those discussed in Sect. 2.1, although this silence can be viewed as preserving: “... a core set of ecosystem accounts to support a wide range of decision-making contexts" (UN 2021, para. 11.48, p. 240). Indeed, UN (2021) does briefly anticipate such issues in suggesting, for example, that: “... data from cadastres showing the sector of ownership or the nature of the tenure can be linked to data on ecosystem assets, and hence provide a basis for monitoring the effects of land management policies within a given region, e.g., a water catchment" (para. 3.85, p. 59) and that "[I]ndicators from the SEEA EA could also be designed to address distributional and environmental justice issues ..." (para. 14.18, p. 309).

Hence, what we propose essentially can be thought of as a cross-classification or an extension of more conventional SUTs that have typically been used in NCA. For example, the picture of ecosystem service use in these SUTs could straightforwardly develop detail on how air pollution removal services are consumed across different households perhaps distinguished by socioeconomic grouping (see Sect. 4.2). Yet, as constructed, the supply portion of panel (a) in Fig. 1 does not provide a basis for looking at possible distributional questions with regards to landholders. By assumption, the focus is instead on ecosystem type as the producing unit. To examine these issues what is needed is, in effect, an overlaying of the standard SUT for ecosystem services with this additional information.

This is described in panel (b) of Fig. 1. What is changed is the lower portion of the panel, which now describes how ecosystem service supply can be attributed to natural capital on land which has an identifiable landholder such as a legal owner. We distinguish between two broad categories of landholder: those in the private and public sector, discussed further in Sect. 3. To reiterate, an interpretation of our approach therefore is that it augments, or overlays, the standard Supply Table in panel (a). That is, we cross-classify this standard way of presenting data on the supply of ecosystem services with information on landholdings on which ecosystem types are located.

In principle, this landholder could refer to owner-occupier or tenant. This would be especially important if what is of primary interest is the economic unit that is responsible for use and management of the landholding. Our empirical focus, as elaborated further in the remainder of this paper, is on the legal owner-whether an occupying or absent

\footnotetext{
${ }^{10}$ In the case of carbon sequestration, as noted by Vallecillo et al. (2019), one way of conceptualizing this is the provision an ecosystem service that is used by institutional units not only in the country to which the SUT applies but also in the rest of the world. So far carbon units from UK voluntary carbon markets (the Woodland Carbon Code) can only be issued by economic units (not open to households) based in the UK.

11 This, in turn, can be used to explore indirect dependencies given that the SUTs can be used as the basis for input-output tables.
} 
landlord-in terms of the supply of ecosystem services. Whether this focus matters is partly an empirical question given that the relative importance of owner-occupied and tenanted land varies across countries as well as differing in terms of the length of those tenancy agreements. For example, in the context of the agricultural sector, a majority of land area is owner-occupied in the UK (Lawrence and Dandy 2014) and the US with, by contrast, tenancies being quantitatively more significant in many EU Member States (Graubner 2018).

Our discussion in Sect. 2.1 was also suggestive of the particular importance of landownership in debates about wealth distribution and political influence in shaping land-use or natural capital policies. In addition, how policy benefits and costs are distributed between (absent) landowner and tenant might also be of interest as indicated by the parallel debate in studies of the way in which (decoupled) direct payments to farmers boost the income of tenants or are reflected in the rents received by landowners (e.g. Graubner 2018; Varacca et al. 2021), although less is known regarding the (ultimate) beneficiaries of explicitly ecosystem-related payments in this regard (although see Salhofer and Feichtinger 2020).

It is worth noting that our emphasis on landowners does not require an assumption or assertion that these actors (or, indeed, landholders more generally) actually own ecosystem assets. Rather our approach is premised on the observation that these assets, being recorded in a NCA, are often located on land that does have a formal owner. The issue of ownership of ecosystem assets and services, however, has been the subject of a mini-literature. This starts from the (distinctive) definitions of legal owner and economic owner as per the System of National Accounts (SNA). The latter, in particular, refers to the economic unit that is entitled to claim the benefits associated with the use of an asset (e.g. UN 2009, $\mathrm{p}$ 195). For example, in the case of agriculture, the economic unit that is using land is recognized as the claimant of the output from agriculture production on farmland in the national accounts. Of course, as NCA often shows, the supply of ecosystem services may also take place as a secondary activity on this same land. But, as discussed in van de Ven et al. (2019), attributing this (secondary) output to an economic unit requires further judgements as to whom is the economic owner of ecosystem asset(s) and ecosystem services.

Vincent (2015), for example, does argue for attributing ecosystem service supply to the user of farmland. Edens and Hein (2013) also explore the implications of this compared to the case where a new sector-labelled "Ecosystems"-is designated as the economic owner. In Campos et al. (2019) the notion of this new sector is refined further to be "Government" given the role of public policy in influencing how natural capital is managed on behalf of wider society, and in its stewardship of nature itself. In the SEEA-EA, UN (2021) arbitrates this debate by partitioning, for accounting purposes, an ecosystem asset into two parts and assigning each part to a different economic owner. The partition is based on whether the supply of ecosystem services are SNA benefits (privately consumed) or non-SNA benefits (publicly consumed). The former are assigned to "landholders" while the latter are assigned to general government as an "ecosystem trustee".

While seemingly abstruse, such discussions are important for determining how NCA might be integrated into national accounts. This, in turn, will have a bearing on the construction of any associated Social Accounting Matrix (or SAM), which is a prominent, and long-established, way of looking at distributional issues in relation to national accounts (e.g. Mainar-Causapé et al. 2018; UN 2018). This is significant for a number of reasons, not least that judgements about the economic owner of ecosystem assets determines how novel accounting aggregates (such as degradation-adjusted net value-added and net saving) are distributed across sectors and economic units comprising the overall economy (see, for example, La Notte and Marques 2019). While this is an important matter for future 
work, for present purposes, however, the most straightforward way of thinking about the distributional issues that we identify is via associated SUTs, without necessitating arguable assumptions about economic ownership. This also has the advantage of being aligned with existing frameworks in NCA, thus illustrating how and where the distributional detail we consider in this paper extends this thinking.

\section{Spatial Distribution of Landownership and Ecosystem Services in Scotland}

In this section we set out our data sources, data analysis and analytical criteria used for our NCA distributional analysis with its focus on carbon sequestration and air pollution removal services as well as extent of ecosystem asset or types. We illustrate this in the context of Scotland and, in particular, its land ownership in relation to where ecosystem assets are located and, in effect, ecosystem services are supplied. The Supplementary Material (see Section S2) for the current paper provides additional detail and we refer to this at various points later on.

The data we use to construct this picture of how land ownership is distributed in relation to natural capital accounts comprise the period 2014-2017. It is important to note that our application—given these available data—does not allow a time-series over this period. Rather we make use of the latest period physical or monetary data that are available, falling within this period. While using a time series or even a consistent accounting year is an important issue, given available data, our results might be tentatively interpreted as relating to a single illustrative year which we take as being 2016 (and so present monetary data in 2016 prices).

\subsection{Land Cover and Landownership Distribution in Scotland}

Scotland covers about 8 million hectares of land. Heather and heather grassland, enclosed farm, woodland, and semi-natural grassland are, in that order, the main broad habitats characterizing land cover (CEH 2017). In terms of land use, agriculture is the predominant use in Scotland, accounting for around $70 \%$ of land, while forest cover is close to $19 \%$ of total land (most of which are coniferous plantations). Land more suitable for agricultural cultivation is concentrated in lowland areas of the East coast, and through the Central belt and Ayrshire in the South West. Much of the remainder of Scotland is more constrained in terms of agricultural potential (e.g. grassland and rough grazing) as it is at higher altitudes (Fig. 2).

Relevant differences in landownership are observed for agricultural and forest land cover. About 35 percent of woodland areas in Scotland belongs to National Forest Estate holdings (Forestry Commission 2018), while most agricultural land is in private hands. The question of who owns the land and the issues arising from the scale of landownership concentration in Scotland is long-standing and has proved politically contentious. ${ }^{12}$

\footnotetext{
12 Scotland, historically, has a highly concentrated system of land ownership that is feudal in origin. This feudal system of land tenure formally was brought to an end on 28 November 2004 when The Abolition of Feudal Tenure (Scotland) Act 2000 came into force. This was replaced in law with a system of outright ownership of land (see Combe et al. 2020 for details).
} 


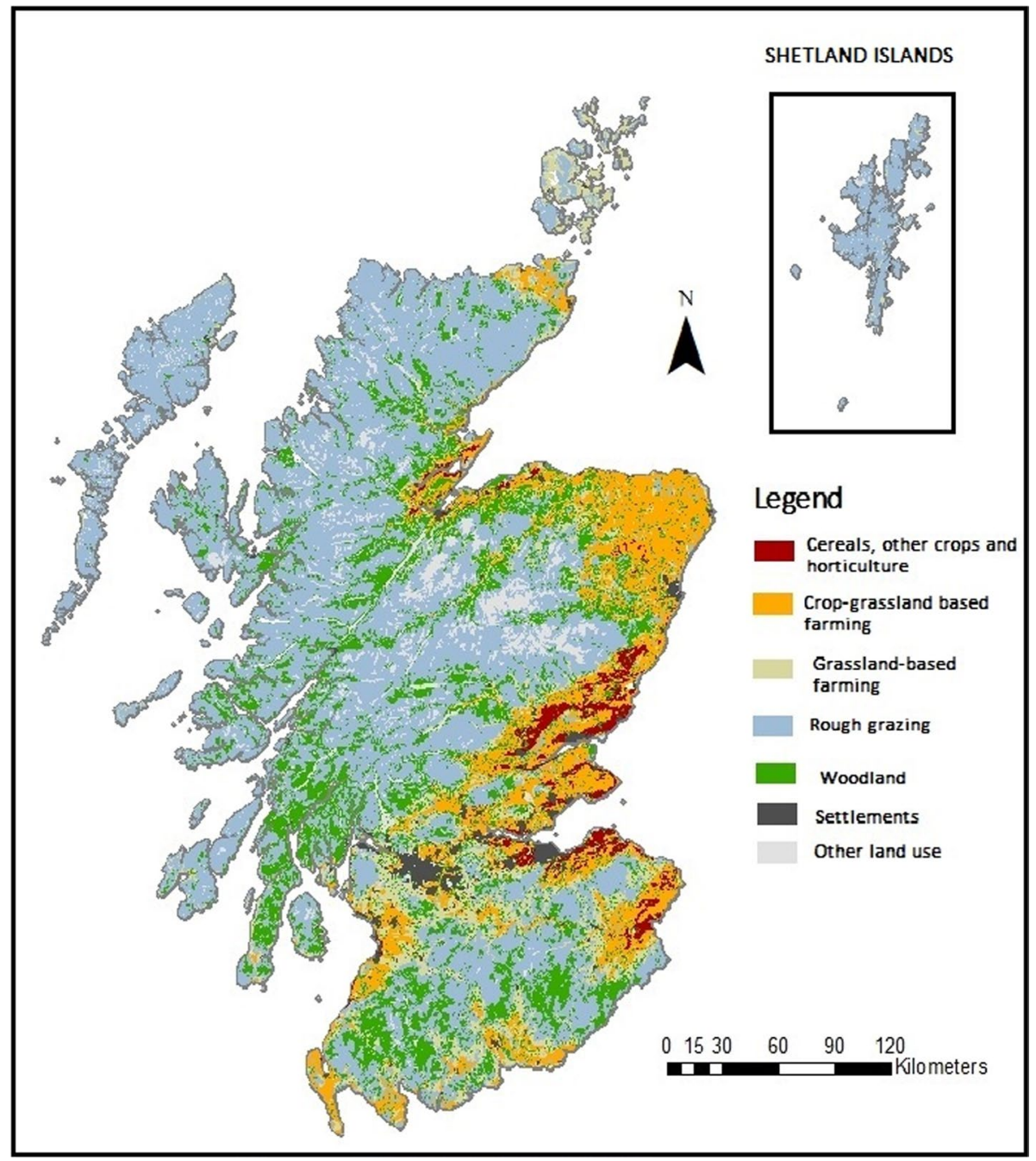

Fig. 2 Land use distribution in Scotland ${ }^{(1)}$. Source: Own elaboration based on (1) The Land Capability for agriculture copy right and data base (C) The James Hutton Institute (2018). Used with permission of the James Hutton Institute. All rights reserved; and (2) Scotland's National Forestry Inventory data (2018) (Forestry Commission, 2019). (C) Crown copyright and data right (2018). Ordnance survey $(100,021,242)$; and Settlement areas under OS Open data (April 2019). Reproduced with permission under the Open Government Licence v 2.0. Created 28.01.2020. Notes: ${ }^{(1)}$ Agricultural land use (crop, grassland, and rough pasture areas) in Scotland depicts a high correspondence with capability of land for agriculture, as shown in McVittie et al. (2019). Figure 2 makes use of a map of land capability for agriculture to estimate the location of broad agricultural land use categories

Landownership is viewed by many as highly concentrated in Scotland and dominated by a small number of private owners. We provide the substance for this claim by presenting next a comprehensive, although partial, picture of land ownership distribution in that country.

Our landownership distribution picture is partial because important gaps in public records on landownership make it very difficult to be precise about the type of owner of 
Table 2 Estimated total and public rural land in Scotland. Source: Own elaboration based on the above referred maps and data sources

\begin{tabular}{|c|c|c|c|c|}
\hline \multirow[t]{2}{*}{ Class } & & \multicolumn{2}{|l|}{ Land area } & \multirow[t]{2}{*}{ Source } \\
\hline & & ha & $\%$ & \\
\hline Total land & & $7,923,165$ & 100.0 & Ordnance Survey (2019) \\
\hline \multirow[t]{3}{*}{ Urban areas } & Settlements' boundaries & $175,004.8$ & 2.2 & NRS (2016) \\
\hline & $\begin{array}{l}\text { Transport network, indus- } \\
\text { try, retail, infrastructure } \\
\text { sites }\end{array}$ & 23,000 & 0.3 & Estimated \\
\hline & Estimated total & $198,004.8$ & 2.5 & Estimated \\
\hline Estimated rural land & Estimated total & $7,725,161$ & 97.5 & Estimated as residual value \\
\hline Owner & Property & Land area & $\%$ & Source \\
\hline Total public land & Estimated total & 895,294 & 11.3 & \\
\hline Crown & Crown Estate & 35,500 & 0.4 & Elliot et al. (2014:52) \\
\hline \multirow[t]{6}{*}{ Scottish Government } & National Forest Estate & 633,859 & 8.0 & Scottish Government (2019) \\
\hline & Crofting Estates & 95,200 & 1.2 & Elliot et al. (2014:52) \\
\hline & Scottish Natural Heritage & 34,435 & 0.4 & SNH (2018) \\
\hline & Scottish Water & 24,300 & 0.3 & $\begin{array}{l}\text { Based on Elliot et al. } \\
\quad(2014: 52)\end{array}$ \\
\hline & $\begin{array}{l}\text { Highlands \& Islands } \\
\text { Enterprise }\end{array}$ & 4,000 & 0.1 & \\
\hline & Estimated Other & 10,000 & 0.1 & \\
\hline Local Government & Estimated Total & 33,000 & 0.4 & \\
\hline UK Government & Ministry of Defence & 25,000 & 0.3 & \\
\hline Total community land & Community Ownership & 209,810 & 2.6 & \\
\hline $\begin{array}{l}\text { Rest of land (assumed } \\
\text { private) }\end{array}$ & Estimated total & $6,620,057$ & 83.6 & Estimated as residual value \\
\hline
\end{tabular}

each parcel of rural land in Scotland. This data gap makes even a superficially simple question-e.g. what is the share of rural land that is in private hands? - not straightforward to answer. What is known, however, is that most land property in Scotland is privately held. Just over $11 \%$ of land in Scotland is in public hands: this is mainly held by the Scottish Government and to a lesser extent by local government and the Crown Estate (Elliot et al. 2014). Community landownership accounts for about $2.6 \%$. This suggests a residual value of 83.6 percent of rural land that is likely to be privately owned (Table 2).

We use Andy Wightman's Who owns Scotland (2015) database to analyze spatial aspects of landownership distribution in Scotland. This map covers about 3.9 million hectares of land, representing nearly half of the total land mass in the country. This also accounts for about 60 percent of privately-owned land (an area estimated as a residual value between total land area and public land in Table 2).

The share of land covered in the Who owns Scotland map varies spatially. Figure 3a shows the spatial distribution of the private properties recorded in this map, along with publicly owned land. The latter includes National Forest Estate holdings as well as (albeit incomplete) Crown Estate Scotland and Scottish Natural Heritage (Nature Scots) properties. This Figure offers a partial cover of rural landownership, with relatively large 


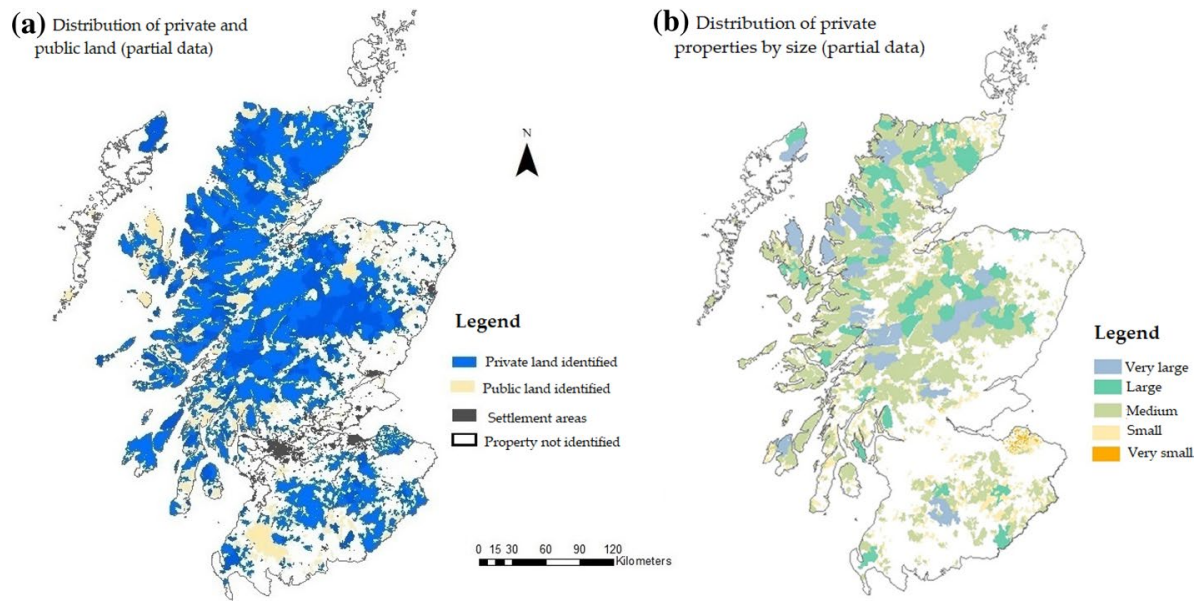

Fig. 3 Landownership and property size distributions in Scotland (partial cover). Source: Own elaboration based on Who owns Scotland property map (2015), and National Forest estates map (Scottish Government (2019), and Settlement areas under OS Open data (April 2019). Reproduced with permission under the Open Government Licence v 2.0. The James Hutton Institute. Created 21.01.2020

Table 3 Private land distribution by property size class (partial data for Scotland). Source: Own elaboration based on Who owns Scotland map (2015)

\begin{tabular}{|c|c|c|c|c|c|c|c|c|}
\hline \multirow[t]{2}{*}{$\begin{array}{l}\text { Property size } \\
\text { class }\end{array}$} & \multirow[t]{2}{*}{$\begin{array}{l}\text { Size criteria } \\
(\text { ha })^{\mathrm{a}}\end{array}$} & \multicolumn{2}{|c|}{$\begin{array}{l}\text { Number of } \\
\text { properties }\end{array}$} & \multicolumn{2}{|c|}{$\begin{array}{l}\text { Size of property } \\
(\mathrm{ha})^{\mathrm{b}}\end{array}$} & \multirow{2}{*}{$\begin{array}{l}\text { Number of } \\
\text { different } \\
\text { owners }^{c}\end{array}$} & \multicolumn{2}{|c|}{$\begin{array}{l}\text { Total private land } \\
\text { area considered }\end{array}$} \\
\hline & & $\mathrm{N}^{\mathrm{o}}$ & $(\%)$ & Mean & SD & & Hectares & $\%$ \\
\hline Very Small & $<100$ & 611 & 23.7 & 36.7 & (29.7) & 248 & 22,449 & 0.6 \\
\hline Small & $<1,000$ & 1,238 & 48.1 & 392.5 & $(227.0)$ & 1,063 & 485,855 & 12.5 \\
\hline Medium & $<10,000$ & 661 & 25.7 & $3,285.2$ & $(2,279.0)$ & 592 & $2,171,528$ & 55.7 \\
\hline Large & $<20,000$ & 47 & 1.8 & $14,468.8$ & $(2,759.9)$ & 47 & 680,033 & 17.4 \\
\hline Very Large & $\geq 20,000$ & 18 & 0.7 & $29,853.0$ & $(6,484.1)$ & 18 & 537,354 & 13.8 \\
\hline Total & & 2,575 & 100.0 & $1,513.5$ & $(3,518.5)$ & 1,735 & $3,897,219$ & 100.0 \\
\hline
\end{tabular}

${ }^{a}$ Size criteria proposed by Hindle et al. (2014: 30). ${ }^{\mathrm{b}}$ Average size per category, standard deviation (SD) in parenthesis. ${ }^{c}$ Different landowners considered in Who owns Scotland map. Some landowners own different properties of different size; hence the total number of landowners does to correspond to the sum of the number of landowners by property size class

parts of the Scottish Islands, the Grampian (North East), Central and South regions of Scotland not covered in the Who owns Scotland data base (see Supplementary Information to the current paper section S.1 for the area covered by local authority in Scotland). 
The map in Fig. 3b records 2575 private properties belonging to about 1735 different private individuals or organizations (i.e., firms, Trusts, Charities). ${ }^{13}$ The size of rural properties mapped here is relatively heterogeneous, with an average area of $1513( \pm 3,518)$ hectares. About half of the properties have sizes of less than one thousand hectares and only cover a combined $12 \%$ of the private land mapped. These relatively smaller properties are mainly owned by individual landowners.

Concentration of landownership in Scotland is further evidenced by the fact that 657 individual owners and organizations own $51 \%$ of total rural land in Scotland (Table 3). This latter share of land accounts for medium to very large properties which are distributed across the country (Fig. 3b). We also observe that where there are data about landownership in North-East and South-East Scotland properties tend to be small to medium size in areas dominated by arable land used for cereals, other crops, horticulture, or cropbased farming while in areas with limited agricultural value (grassland, rough grazing) and woodland, properties are of a medium to very large size class.

We turn now to focus on landowners as suppliers of two ecosystem services: air pollution removal and carbon sequestration. While we have argued previously that distributional issues arguably exist with respect to ownership, a more general approach would look additionally at all land managers (including landholders such as tenants as well as landowners making use of their own land). Hence, a caveat of our analysis is that we are not able to comment on the supply of ecosystem services in terms of distributional issues characterizing those who are always directly connected with land management practices and decisions. That said, owner-occupied landholdings are significant in Scotland with only about 22 percentage of the total agricultural area being rented (Scottish Government 2020a, p.13).

As previously indicated, another caveat is that our landownership data are incomplete and the property size classes, in Table 3, do not represent land owned in some areas most suited for crops (Fig. 2). For instance, an official report on the structure of agricultural farms in Scotland show that agricultural Parishes within North East Scotland and the Central belt are dominated by agricultural holdings of sizes that fluctuate between 20 and 100 ha (Scottish Government 2016). According to the same source, it is further estimated that $52 \%$ of holdings comprise only 1.6 per cent of the total land, consisting of 26,830 holdings of less than ten hectares in size.

More research is needed to complete the landownership and usership database in Scotland. A database such as the Integrated Administration and Control System (IACS), used to support rural payments in the framework of the Common Agricultural Policy (CAP) in Scotland, could help in both regards. At the EU level current efforts to complete land survey and cadastral data across whole national territories represent an opportunity also to add a landownership layer to the SEEA-EA. Systems such as IACS then might add the usership component. Having adding both information layers alongside ecosystem accounts or NCA might then provide the basis to monitor and evaluate the effect, or potential effect, of land management policies.

\footnotetext{
13 A Trust is a legal entity created by a party (the trustor) through which a second party (the trustee) holds the right to manage the trustee's assets or property for the benefit of a third party (the beneficiary). A charity is an organization with specific purposes defined in law to be charitable - and is exclusively for public benefit. Some Trusts such as The Woodland Trust or the Scottish Wildlife Trust are registered as charities, and for the purposes of this study considered under the charity category.
} 


\subsection{Spatial Distribution of Air Pollution Removal and Carbon Sequestration Services}

The distributional issues we assess relate primarily to two ecosystem services. One-air pollution removal services-is localized in terms of its impacts on users. The other-i.e. carbon sequestration-is global in terms of the (net) impact on climate stability. While we cannot claim generality by looking at the distribution of a fuller suite of ecosystem services, this focus on a local service and a global service captures key aspects of the problem. Both of these services are also examples of what UN (2021, p.118) refers to as non-SNA benefits: that is, benefits consumed by individuals which are not obviously the outcome of an economic production process currently defined within the SNA boundaries. These are also public ecosystem services: i.e. flows which are (largely) consumed by economic units other than those using or owning land (e.g. such as households in the case of air pollution removal services).

We now summarize the data we use for our assessment of the spatial distribution of air pollution removal and carbon sequestration services. Further details can be found in the Supplementary Information (see sections S.3 and S.4). A common link here is vegetation in providing both an air quality and a global climate regulating service. The former refers to capturing airborne pollutants and removing them from the atmosphere through internal absorption of pollutants via stomatal uptake as well as the deposition of pollutants on external surfaces such as leaves and bark (Jones et al. 2017; Nemitz et al. 2020). The latter refers to uptake of carbon dioxide from the atmosphere and the fixing of this gas as carbon into vegetation structures.

Air pollution removed by broad habitats is estimated by the ONS (2018)—building on work in Jones et al. (2017) - for six pollutants $\left(\mathrm{PM}_{2.5}, \mathrm{PM}_{10}, \mathrm{NO}_{2}, \mathrm{NH}_{3}, \mathrm{SO}_{2}\right.$ and $\left.\mathrm{O}_{3}\right)$ across the UK by ecosystem types. The location of vegetation is an important determinant of the quantity and value of air quality regulation it delivers. This is because the amount of service provided depends upon the amount of vegetation, air quality, population, and transport of pollutants. As expected, air quality regulation services are higher in more populated areas, with lower vegetation cover. However, the study by Nemitz et al. (2020) suggests that air pollution concentrations can be lowered also by the uptake of some of the pollutants transported long range from continental Europe by vegetation encountered on the way. And as these authors suggest this may also be relevant in larger Scottish cities such as Glasgow, benefitting from $\mathrm{PM}_{10}$ deposition in the English Midlands.

Figure 4 shows the spatial distribution of air pollutants removal services in Scotland. Where woodlands are present in Scotland, such as in South and South-west of the country (Fig. 2), these have the largest impact on air pollutants deposition (especially, for particulates and ozone).

To estimate net carbon sequestration by forestlands in Scotland, we use a recent report by Clilverd et al. (2019) which has been the basis for ONS and official statistics in this regard. This report provides estimates of both carbon dioxide emissions and removals (through carbon sequestration) to and from the atmosphere by local authority in Scotland. Those estimates include (net) carbon removal by forestland and emissions from soils due to land use change from and to cropland, grassland, and settlements. Given this, our analysis considers average net carbon sequestration values by hectare of forest at the local authority level (see Supplementary Information). 

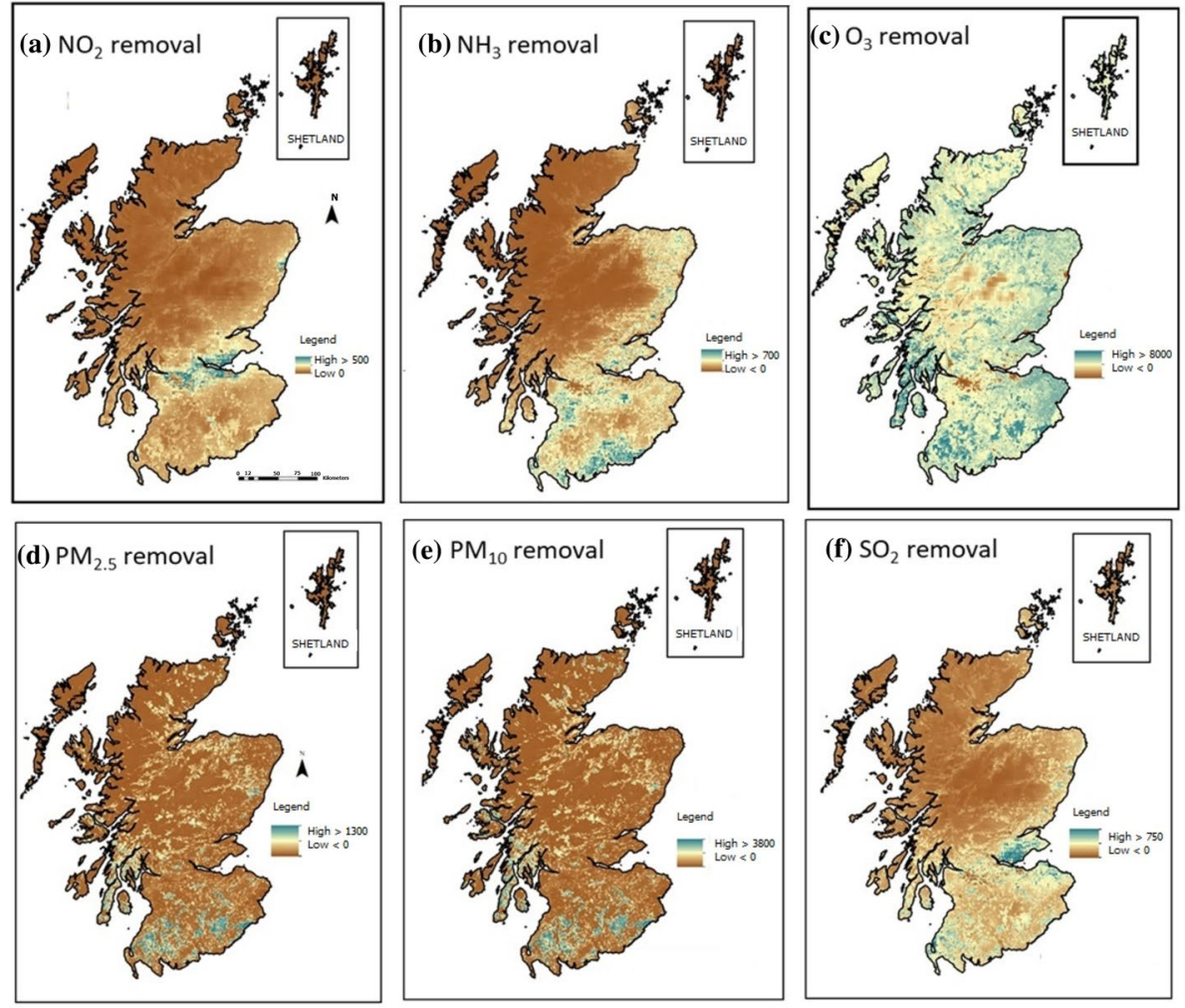

Fig. 4 Net air pollution removal by vegetation and pollutant in Scotland. (2015 data per pollutant in $\mathrm{kg}$ per $1 \mathrm{~km}$ grid square). Source: Own elaboration based on ONS (2018) pollution removal data. Reproduced with permission under the Open Government Licence v 2.0

\section{Results}

\subsection{Delivery of Ecosystem Services}

Aggregated natural capital accounts for carbon sequestration in the UK, indicate that about $71 \%$ of the physical and monetary value associated with this ecosystem service flow was mainly provided by woodland in 2016 . Woodland is also associated with $28 \%$ of air pollution removal service, while enclosed farm, mountainous and moorland areas contribute to $23 \%$ each and semi-natural grassland to $17 \%$ of this service (ONS 2020a). Bearing in mind that most of farmland and more than $50 \%$ of woodland areas is in private hands, we can say that a significant portion of ecosystem services is delivered by privately owned land in Scotland. 
(a) Monetary value air pollution removal

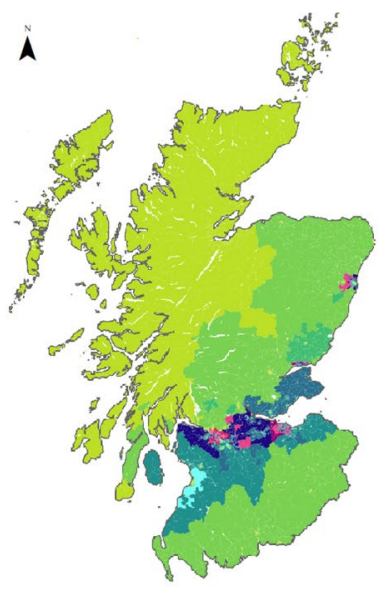

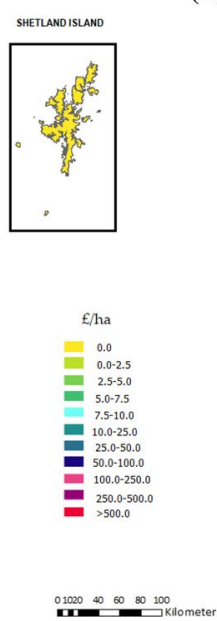

(b) Gross median household income

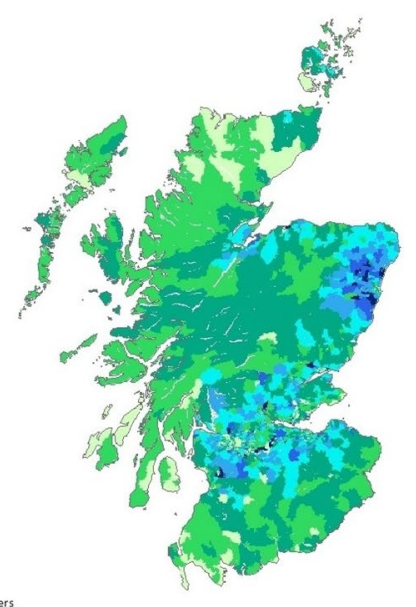

SHETLAND ISLAND

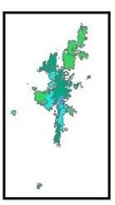

f/week

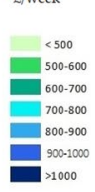

Fig. 5 Avoided health damage costs (in $£$ per hectare, year 2016) compared to gross household income distribution (in £ per week, updated to year 2016). Source: Own elaboration based on (a) ONS (2018) air pollution removal data set, and monetary data on Avoided health damage costs ( $£$ per person, updated to year 2016), and mid-year total population by district and local authority in Scotland; and (b) Weekly local level household gross income in 2015 (Scottish Government 2020b). Gross median income values were updated to 2016 prices. Reproduced with permission under the Open Government Licence v 2.0

\subsubsection{Air Quality Regulation Services}

Figure 5 shows the spatial distribution of the estimated air pollution removal by pollutant in 2015 in Scotland. ${ }^{14}$ This Figure shows that absorption and deposition of $\mathrm{SO}_{2}, \mathrm{NO}_{2}$ and $\mathrm{NH}_{3}$ is greater in areas which are more densely populated (see settlement areas in Fig. 3a). The overall air pollution removal value would depend on the pollutant concentration, which as expected is lower in more remote areas (e.g. the Highlands in the North West). Hence, the monetary values (for flow and asset) associated with air pollution removal would be lower when air quality is higher (and vice versa), other things being equal.

The air pollution removal model for vegetation also permits monetary natural capital accounts (Jones et al. 2017). It does so by considering health benefits in terms of changes in pollutants exposure and avoided health outcomes at the local authority level (e.g. hospital admissions, acute and chronic mortality, see Supplementary material S.3 for more details). Figure 5a shows the estimated spatial distribution of the monetary value associated with air pollution removal by vegetation. Monetary value is defined in terms of avoided costs from the above health outcomes (2012 data updated to 2016 prices) by person and local authority or district in Scotland. The per hectare values in Fig. 5a account for mid-year population by local authority or district, and spatial distribution of total air pollution removal (weighted by the quantity of pollutant instead of by its toxicity).

Figure 5a shows that air pollution removal amounts less than $£ 10$ per hectare of land across much of Scottish territory, with an average value of $£ 9$ per hectare. Nevertheless, there are substantially higher values in a few areas: notably, those in the Central belt. Needless to say, it is not a coincidence that these are also some of the most populated areas. It is this primary factor in combination with the proximity of vegetation and ambient pollution

\footnotetext{
14 The ONS (2020a) physical accounts for air pollution removal indicate a reduction of $0.16 \%$ in the total amount for pollutants removed by vegetation in Scotland in 2016 respect to 2015.
} 
(a) Physical values (2017)

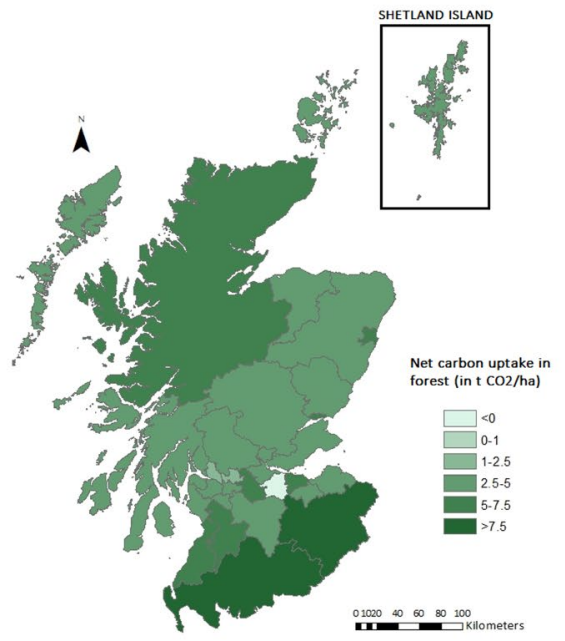

(b) Monetary values (2016)

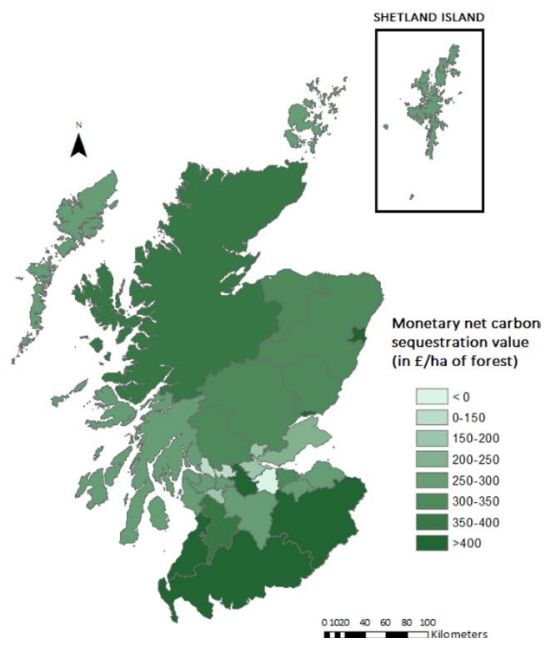

Fig. 6 Estimated net carbon uptake and value by forestland by local authority in Scotland. Source: Own estimations based on 2017 carbon emission and removals in the Land Use, Land Use Change and Forestry Sector (LULUCF) (Clilverd et al. 2019), National Forest inventory data (Forestry Commission (2019), and non-traded carbon sequestration values (year 2016). Reproduced with permission under the Open Government Licence v 2.0

levels that is driving these higher values. Drawing a link to our earlier discussion of distributional detail within a SUT for ecosystem services (see Sect. 2.2), how these values are distributed across people - as users of air pollution removal services-is also of interest.

Figure 5b shows how (gross) median income is distributed across Scotland based on 2015 data from the Scottish Government (2020b). We find, however, a relatively weak positive relationship between gross income and total air pollution removed, which indicates a higher air quality control services in areas of higher incomes, which in Scotland correspond to more densely populated areas.

This, and other related data, are described in more detail in the Supplementary Information to the current paper (see section S.5). In terms of percentage distribution of air pollution removal values our data across local authority areas indicates that typically in excess of $64 \%$ of total value is consumed by those households in the two lowest income ranges (Table S.8 in the Supplementary Information). Nonetheless, the value of this ecosystem service in relation to gross income is relatively low, at least according to our data. Crucially, a lack of spatial data on households by income status prevents further elaboration even were the degree of spatial resolution in the official ONS data for NCA able to lend itself to robust interpretation in terms of environmental justice.

\subsubsection{Global Climate Regulation Through Net Carbon Sequestration by Vegetation}

Figure 6 describes estimated average net carbon uptake per hectare of forestland ${ }^{15}$ by local authority. This figure shows relatively highly aggregated data that does not allow for a

\footnotetext{
15 That is, once emissions from estimated deforestation in settlements and grasslands as well as forest fires are detracted from gross forest carbon sequestration data.
} 
Table 4 Physical distribution of selected ecosystem services by broad habitat in Scotland (2016). Source: ONS (2020a)

\begin{tabular}{|c|c|c|}
\hline \multirow[t]{2}{*}{ Broad habitat } & \multicolumn{2}{|c|}{$\begin{array}{l}\text { Distribution of ecosystem } \\
\text { services }^{\text {a }} \text { by habitat }(\%)\end{array}$} \\
\hline & $\begin{array}{l}\text { Carbon seques- } \\
\text { tration }\end{array}$ & $\begin{array}{l}\text { Air pol- } \\
\text { lution } \\
\text { removal }\end{array}$ \\
\hline Farmland & 29.3 & 23.2 \\
\hline \multicolumn{3}{|l|}{ Cropland } \\
\hline Grassland & 29.3 & \\
\hline Semi-natural grassland & & 17.3 \\
\hline Woodland & 70.7 & 27.9 \\
\hline Mountain, moor, and hill & & 22.8 \\
\hline \multicolumn{3}{|l|}{ Freshwater } \\
\hline Open water, wetland \& floodplain & & 8.7 \\
\hline Costal margin & & 0.1 \\
\hline \multicolumn{3}{|l|}{ Wildlife areas } \\
\hline \multicolumn{3}{|l|}{ Other (non-urban) areas } \\
\hline \multicolumn{3}{|l|}{ Built up areas and gardens } \\
\hline Total & 100.0 & 100.0 \\
\hline
\end{tabular}

${ }^{a}$ Distribution based on physical flows and monetary flows (when available) for year 2016

detailed spatial analysis in the provision of carbon sequestration services. On average, in 2017 each hectare of forest in Scotland sequestered about 5.2 tonnes of $\mathrm{CO}_{2}$. This translates into a monetary value close to $£ 331$ per hectare of forest, when 2016 central nontraded carbon values are considered (BEIS 2012). ${ }^{16}$

The value of net carbon sequestration varies within a range from negative values (i.e. $\mathrm{CO}_{2}$ equivalent emissions) to more than 7.5 tonnes of $\mathrm{CO}_{2}$ per hectare of woodland and year being removed from the atmosphere. It should be noted that this value only accounts for net carbon sequestration in forestland. When changes in soil carbon stock from other land uses - namely grassland, and cropland, and associated land use changes - are considered, net carbon sequestration drops to $0.55 \mathrm{CO}_{2}$ tonnes per hectare of land in Scotland.

\subsection{Landownership and Provision of Ecosystem Services in Scotland}

Tables 4 and 5 give a partial view of the relative contributions of our two ecosystem services by, respectively, ecosystem type (broad habitat) and private and public land in

\footnotetext{
${ }^{16}$ Data available in Table 3 of the data tables supporting the Green Book toolkit and guidance (BEIS 2012).
} 
Table 5 Distribution by type of landholder of two ecosystem services in Scotland

(a) Percentage contribution to the delivery of ecosystem services (partial cover)

\begin{tabular}{|c|c|c|c|c|c|c|}
\hline \multirow[t]{3}{*}{ Ecosystem service } & \multicolumn{5}{|c|}{ Percentage of ES delivered by type of ownership (\%) } & \multirow{3}{*}{$\begin{array}{l}\text { Public } \\
\text { land } \\
\text { (total) }\end{array}$} \\
\hline & \multicolumn{5}{|c|}{ Private land (according to the property size) } & \\
\hline & $\begin{array}{l}\text { Very small } \\
\text { to small } \\
(<1,000 \text { ha })\end{array}$ & $\begin{array}{l}\text { Medium } \\
(<10,000 \text { ha })\end{array}$ & $\begin{array}{l}\text { Large } \\
(<20,000 \text { ha })\end{array}$ & $\begin{array}{l}\text { Very large } \\
(>20,000 \text { ha })\end{array}$ & Total & \\
\hline $\begin{array}{l}\text { Net } \mathrm{CO}_{2} \text { e sequestration } \\
\text { by forest }\end{array}$ & 8 & 36 & 11 & 9 & 64 & 36 \\
\hline $\begin{array}{l}\text { Air pollution removal } \\
\text { physical }\end{array}$ & 32 & 46 & 2 & 1 & 81 & 19 \\
\hline $\begin{array}{l}\text { Air pollution removal } \\
\text { value }\end{array}$ & 35 & 40 & 1 & 0 & 77 & 23 \\
\hline
\end{tabular}

(b) Distributional supply table (GBP, £, millions, 2016 prices)

\begin{tabular}{|c|c|c|c|c|}
\hline \multicolumn{2}{|l|}{ Landholders } & \multirow{2}{*}{$\begin{array}{l}\begin{array}{l}\text { Net } \mathrm{CO}_{2} \text { e seques- } \\
\text { tration }\end{array} \\
223\end{array}$} & \multirow{2}{*}{$\begin{array}{l}\text { Air pollution } \\
\text { removal }\end{array}$} & \multirow{2}{*}{$\begin{array}{l}\text { Total } \\
232\end{array}$} \\
\hline Public & & & & \\
\hline Private & & 396 & 30 & 426 \\
\hline \multirow[t]{5}{*}{ - of which: } & Very large & 56 & $\sim 0$ & 56 \\
\hline & Large & 68 & $\sim 0$ & 68 \\
\hline & Medium & 223 & 16 & 239 \\
\hline & Small to very small & 50 & 14 & 64 \\
\hline & Total & 619 & 39 & 638 \\
\hline
\end{tabular}

${ }^{\mathrm{a}}$ Forest carbon sequestration based upon distribution of public and private forest by local authority

Table 6 Land cover by broad habitat and size of the farm (in hectares). Source: Own elaboration based on Who owns Scotland map (2015) and CEH Land Cover Maps (LCM 2007) (Morton et al. 2011)

\begin{tabular}{lcrrrrr}
\hline Broad habitat/ecosystem type & Very Small & Small & Medium & Large & Very Large & Total \\
\hline Woodland & 2223 & 98,290 & 352,206 & 106,156 & 83,376 & $\mathbf{6 4 2 , 2 5 1}$ \\
Enclosed farm & 1458 & 63,112 & 194,978 & 56,865 & 44,476 & $\mathbf{3 6 0 , 8 8 7}$ \\
Semi-natural grassland & 1369 & 100,274 & 524,301 & 165,899 & 128,810 & $\mathbf{9 2 0 , 6 5 3}$ \\
Dwarf shrub heath & 677 & 121,432 & 731,634 & 226,880 & 189,788 & $\mathbf{1 , 2 7 0 , 4 1 1}$ \\
Bogs & 24 & 13,882 & 91,505 & 30,331 & 20,778 & $\mathbf{1 5 6 , 5 2 1}$ \\
Inland rock & 399 & 7658 & 72,521 & 18,304 & 27,425 & $\mathbf{1 2 6 , 3 0 7}$ \\
Freshwater and wetland & 148 & 10,397 & 86,373 & 45,464 & 35,530 & $\mathbf{1 7 7 , 9 1 2}$ \\
Coastal margins & 12 & 3727 & 13,484 & 3410 & 4834 & $\mathbf{2 5 , 4 6 6}$ \\
Urban and sub-urban & 320 & 10,685 & 21,779 & 11,130 & 9259 & $\mathbf{5 3 , 1 7 3}$ \\
Total & $\mathbf{6 6 3 1}$ & $\mathbf{4 2 9 , 4 5 6}$ & $\mathbf{2 , 0 8 8 , 7 8 2}$ & $\mathbf{6 6 4 , 4 3 8}$ & $\mathbf{5 4 4 , 2 7 4}$ & $\mathbf{3 , 7 3 3 , 5 8 0}$ \\
\hline
\end{tabular}

Totals may not correspond to row or column sums due to rounding 
Scotland. These are estimations based on available information on public and private forest and rural land distribution.

The relevance of public and private land for carbon sequestration is estimated considering both the net carbon sequestration (Fig. 6) and the partial distribution of private land by property size and public land by local authority. The results indicate that $64 \%$ of net carbon sequestration by forestland occurs in private forest areas. A large portion of this carbon sequestration (56\%) apparently occurs in medium to very large properties.

One important contrast with air pollution removal is the relative higher relevance of smaller properties in providing this air quality regulating service. Smaller properties are more frequent in the Central belt, which is also the area of highest population density within Scotland (i.e., Greater Glasgow, Ayrshire, Falkirk, Edinburgh, Lothian, and Fife). However, the information gaps on landownership are relevant in this region (Fig. 3), where air pollution removal by vegetation is expected to have a higher monetary value (Fig. 5). This suggests that our results overstate concentration as what is missing from a comprehensive assessment of land ownership is likely to be smaller properties, notwithstanding to some extent the existence of multiple ownership of smaller properties as indicated in Table 3.

In aggregated terms, air pollution removal had a monetary value of $£ 39$ million for the areas covered in this study (2016 prices). The monetary value of carbon sequestration in this same period and study area amounts to $£ 619$ million. These values represent 54 percentage and 86 percentage, respectively, of the total air pollution and carbon sequestration services monetary flows estimated for the whole Scotland for the period 2016 (ONS 2020a), also expressed in 2016 prices for purposes of comparison (Table 1). Air pollution and carbon sequestration values covered in this study account for less than $0.03 \%$ and for about $0.4 \%$ of Scottish GDP in 2016, respectively. Table 5(b) illustrates the distribution of these values in monetary terms.

Helm (2019) argues what is important is the balance sheet. By this he means not necessarily the present value of the flow of ecosystem services, but the extent (and perhaps condition) of the underlying asset. Table 6 provides a physical statement on these lines - at least with regard to extent-by describing the nine ecosystem types in the natural capital account for Scotland published by the ONS. Specifically, the Table refers to the extent of ecosystem assets on the private land that we have mapped (using the Who owns Scotland map database) and classified according to the five categories of size of holdings of landowners.

Given the data in Table 6 describes total hectares in each ecosystem type across our five categories of size of landholdings, the influence of the concentration of landownership in Scotland is again apparent. That is, by definition, while a given property in the first two columns of the Table will not be large in terms of hectares the fact that there are relatively few of these properties in this category means that these account for a small proportion of total land area covered by any of the nine ecosystem types.

This is a matter of degree. When compared against the individual categories of large or very large landholdings, ecosystem extent is broadly comparable or greater for some ecosystem types, notably woodland and enclosed farm but also, to a lesser extent, coastal margins and urban and sub-urban. There is a clear preponderance of ecosystem extent being in medium-sized landholdings, apart from in two cases (freshwater and wetland/urban and sub-urban). Table 6 also indicates ecosystem extent within each size category of landholding. Although relatively minor in absolute terms, the proportion of woodland and seminatural grassland within smaller sized landholdings is notable. 


\section{Discussion and Conclusions}

Natural capital accounting (NCA) provides a powerful framework for organizing otherwise voluminous information on ecosystem assets - and natural capital more generally-as well as the flow of services that these assets produce. This, in turn, provides a systematic basis for addressing a correspondingly large number of economic and policy questions.

How natural capital is distributed also matters. Indeed, this is acknowledged by the growing attention given to spatially explicit NCA. This increasingly emphasizes the locality and location of natural capital, as the basis for more effective and economically efficient policy formulation. Given this emerging centrality of NCA to decision-making, it becomes ever more important that this work is also aligned to providing answers to distributional questions.

In this paper, we have couched this in terms of identifying distributional issues in the supply and use of ecosystem services and location of ecosystem assets (defined as ecosystem types). To do so, in our empirical application to Scotland, we have focused on two categories of ecosystem service: air pollution removal and carbon sequestration services. These two distinct flows provide a useful contrast given that, in the latter, the location of the ecosystem asset 'does not matter' at least in terms of the use of the ecosystem service by people, and in the former it does. That is, in the case of air pollution removal what is often important is relative proximity of an ecosystem asset, providing this service, to users in relatively populated areas.

In principle, this permits the exploration of concerns relevant to environmental justice with respect to use of air pollution removal services by households differentiated by, for example, income category. In practice, however, while we do find some indication of the use of this service skewing towards certain income groups, monetary value is low in relation to income and crucially spatial data on households by income group are lacking.

In this respect, our primary focus has been on the supply of ecosystem services, in terms of ownership of the land where the ecosystem assets-giving rise to these services-are located. As we discuss the empirical challenge is not inconsiderable, not least given what is publicly known and available about landownership and the spatial disaggregation of existing NCA. In this respect, however, our application to Scotland provides a useful setting to assess the scope for exploring distributional issues in NCA.

Our key findings are as follows. The primacy of private land ownership in Scotland makes clear that these actors have a central role in the supply of the ecosystem services that we examine. We also throw light on the way in which the supply of ecosystem service, and the underlying ecosystem asset, is distributed across landowners characterized by size of their landholding. For example, we find that more concentrated land holdings appear to be relatively important for (net) carbon sequestration services whereas there is a greater tendency for smaller and medium sized holdings to be significant in the supply of air pollution removal services.

Our findings should not be interpreted as meaning that landowners own ecosystem assets, although clearly these actors are the legal owners of the (land) asset on which this natural capital is located. In our case study these actors are also, for the most part, the economic owner of this land too given the preponderance of owner-occupied landholdings in Scotland (and the UK generally).

Yet, who owns, and manages, natural capital might be a secondary concern so long as public policy regimes succeed in provides sufficient flows of public ecosystem services 
to users, perhaps further ensuring these flows are reasonably equitably distributed in use. However, the concern of others about how the land is owned relates to a point made in broader wealth inequality debates. While our results do not provide a commentary on wealth in-the-round (e.g. to what extent are large landowners wealthy in other respects), these concerns about wealth distribution relate to natural capital policy processes. The argument, for example, might be that larger landowners can use their power and position to influence the terms of natural capital policy in their favour. Presumably, this leverage is all the more significant as the value of public ecosystem services is increasingly recognized in statistical venues such as NCA. ${ }^{17}$

This especially might be the case if novel payments translate de facto natural capital ownership into income and wealth for landholders. More generally, understanding who might benefit from policy interventions that seek to maintain and enhance natural capital could reveal, in turn, how wealth distribution changes as a result of otherwise desirable and innovative policies. An effective scheme, in any event, will require information about who are the recipients and what it is that they supply. In this sense, our empirical analysis is simply based on the sorts of data that might be required on landholders and landownership, regardless of whether policymakers are concerned about distributional issues (see Maes et al. 2018 for a discussion of informational demands). But given that natural capital policy additionally will have distributional consequences, NCA has a role to play in anticipating these potential issues. This, in turn, may frame discussions about the public perceptions of fairness in these policies given these distributional implications (e.g. Atkinson, 2009; Mazzacuto 2018).

That said, drawing on evidence from natural capital accounts presents only a snapshot of the ownership of ecosystem assets and distribution of supply of ecosystem services-in the current period (e.g. an accounting year). Actual policy initiatives might be envisaged as applying to additional supply of some ecosystem service (relative perhaps to current provision or some other baseline or reference point). Or it might be conceived in terms of maintaining and improving the condition of ecosystem assets. Nature Scots (2021), for example, is currently testing outcome-based payments depending on generic outcomes, reflecting ecological condition, such as hedge quality or grassland species diversity or peatland quality. While beyond the scope of the current paper, this suggests that it would also be interesting to know how ecosystem condition varies across landholdings of different size and the extent to which NCA can be an organizing framework for such information.

Our empirical application for Scotland represents a case where existing land inequality lends itself naturally to posing distributional questions of NCA. A number of extensions to our research also suggest themselves. For example, expanding the ecosystem services considered would reveal whether this reinforces our findings, and the contrasts between the carbon sequestration and air pollution removal cases. However, our emphasis on distributional issues in NCA should be of considerable interest beyond the Scottish or the UK settings. Questions about ecosystem service use are relevant in many country contexts as the literature on environmental justice attests. Extending distributional issues in supply to ecosystem condition accounts might, in addition, start to connect NCA with questions addressed elsewhere about the connection between land inequality and ecosystem loss or degradation (e.g. McDonald et al. 2010; Albuquerque Sant'Anna 2016; Ceddia, 2019). But, more generally, contributions such as Bauluz et al. (2020) make clear the potential

\footnotetext{
17 This is all the more so given the critique in NCC (2020) that the values of aggregate natural capital in, for example, ONS (2020a) - that we draw upon in the current paper - are highly conservative (i.e. too low).
} 
relevance of the land inequality context to NCA, and the supply of ecosystem services, around the world. Such distributional issues deserve to be more at the heart of NCA, especially as this measurement tool becomes ever more present and integrated within the balance sheets of nations.

Supplementary Information The online version contains supplementary material available at https://doi. org/10.1007/s10640-021-00613-6.

Acknowledgement Paola Ovando acknowledges the financial support of the Macaulay Development Trust though the Fellowship on Natural Capital, while she was working at the James Hutton Institute, in Scotland. The authors thank Keith Matthews, Kirsty Blackstock, Annie McKee, and Michela Faccioli for their valuable comments and suggestions to the early version of this manuscript, and Gianna Gandossi for providing mapping support. Authors also thank the feedback from the participants of the Natural Capital Accounting session at the EAERE 2020 conference, and the participants of the DEFRA lunch Seminar 16.07.2020. The authors are immensely grateful to two anonymous reviewers for their comments and suggestions that allowed us to improve this paper. This paper reflects only the authors views and not the views of the supporting institutions or other individuals.

Open Access This article is licensed under a Creative Commons Attribution 4.0 International License, which permits use, sharing, adaptation, distribution and reproduction in any medium or format, as long as you give appropriate credit to the original author(s) and the source, provide a link to the Creative Commons licence, and indicate if changes were made. The images or other third party material in this article are included in the article's Creative Commons licence, unless indicated otherwise in a credit line to the material. If material is not included in the article's Creative Commons licence and your intended use is not permitted by statutory regulation or exceeds the permitted use, you will need to obtain permission directly from the copyright holder. To view a copy of this licence, visit http://creativecommons.org/licenses/by/4.0/.

\section{References}

Albuquerque Sant'Anna, A. (2016) Land inequality and deforestation in the Brazilian amazon. Environ Dev Econ 22:1-25

Atkinson AB (2009) Factor shares: the principal problem of political economy? Oxf Rev Econ Policy 25(1):3-16

Barbier EB (2018) Reconciling inclusive wealth and piketty: natural capital and wealth in the 21st century. In: Managi S, Kumar P (eds) Inclusive wealth report 2018: measuring progress towards sustainability. Routledge, London

Barbier EB (2011) Capitalizing on nature: ecosystems as natural assets. Cambridge University Press, Cambridge, $\mathrm{p} 337$

Bateman IJ, Mace GM, Fezzi C, Atkinson G, Turner K (2011) Economic analysis for ecosystem service assessments. Environ Resource Econom 48:177-218

Bański (2017) The consequences of changes of ownership for agricultural land use in central European countries following the collapse of the eastern bloc. Land Use Policy, 66:120-130

Bauluz L, Govind Y, Novokmet F (2020) Global land inequality”, WID world Working Paper No. 2020/10, World Inequality Database/ World Inequality Lab

Begon M, Townsend CR, Harper JL (2006) Ecology: from individuals to ecosystems, 4th edn, Wiley, New York $750 \mathrm{pp}$

BEIS (2012), Green Book supplementary guidance: valuation of energy use and greenhouse gas emissions for appraisal, Department for Business, Energy and Industrial Strategy. Available online: https://www. gov.uk/government/publications/valuation-of-energy-use-and-greenhouse-gas-emissions-for-appraisal [last accessed 04 Jun 2020]

Benra F, Nahuelhual L (2019) A trilogy of inequalities: land ownership, forest cover and ecosystem services distribution. Land Use Policy 82:247-257

Boushey H, DeLong JB, Steinbaum M (eds) (2017) After Piketty: The agenda for economics and inequality. Harvard University Press, Cambridge, Mass, 688 pp

Bright G, Connors E, Grice J (2019) Measuring natural capital: towards accounts for the UK and a basis for improved decision-making. Oxf Rev Econ Policy 35(1):188-108

Bromley DW (1991) Environment and economy: property rights and public policy. Basil Blackwell, Oxford 
Bromley DW, Hodge I (1990) Private property rights and presumptive policy entitlements: reconsidering the premises of rural policy. Eur Rev Agric Econ 17:197-214

Brown GM, Shogren JF (1998) Economics of the endangered species act. J Econ Perspect 12(3):3-20

Cahill K (2001) Who Owns Britain?, Canongate, Edinburgh

Campos P, Caparrós A, Oviedo JL, Ovando P, Álvarez-Farizo B et al (2019) Bridging the gap between national and ecosystem accounting application in Andalusian forests, Spain. Ecol Econ 157:218-236

Ceddia MG (2019) The Impact of income, land, and wealth inequality on agricultural expansion in Latin America. Proc Natl Acad Sci 116(7):2527-2532

CEH (2017). Land Cover Maps 2015 (LCM 2015) Statistics. Centre for Ecology and Hydrology. Available online: https://www.ceh.ac.uk/land-cover-map-2015-statistics [last accessed 19/05/2020].

Christophers B (2018) The New Enclosure: the appropriation of Public Land in Neoliberal Britain. Verso, London, p 304

Clilverd H, Buys G, Thomson A, Malcom H, Henshall, P, Matthews R (2019) Mapping Carbon emissions \& removals for the land use , land use change \& forestry sector. Report based on the 1990-2017 inventory. Centre for Ecology and Hydrology

Combe MM, Glass J, Tindley A (2020) Introduction. In: Combe MM, Glass J, Tindley (eds) Land Reform in Scotland. History, Law and Policy. Edinburgh University Press, Edinburgh, pp 1-20

Cornes R, Sandler T (1996) The Theory of Externalities, Public Goods, and Club Goods. Cambridge University Press, Cambridge, p 590

DeLong JD, Boushey H, Steinbaum M (2017) Capital in the Twentieth Century, Three Years Later. In: Boushey H, DeLong JD, Steinbaum M (eds) After Piketty: the agenda for economics and inequality. Harvard University Press, Cambridge

Edens B, Hein L (2013) Towards a consistent approach for ecosystem accounting. Ecol Econ 90:41-52

Elliot A, Watt J, Cooke I, Tabor P (2014). The Land of Scotland and the Common Good. Report of the Land Reform Review Group. Scottish Government, 262 pp

Eurostat (2020) Farms and farmland in the European Union - statistics. Available online: https://ec.europa. eu/eurostat/statistics-explained/index.php/Farms_and_farmland_in_the_European_Union_-_statistics (last accessed 13 Apr 2021)

Faccioli M, Zonnevel S, Tyler C, Day B (2019) Local natural capital accounting: does it deliver useful management information? A case study of Dartmoor and Exmoor National Parks, LEEP, University of Exeter, Exeter

Forestry Commission (2019) National Forest Inventory Woodland Scotland 2018. Available online at http:// data-forestry.opendata.arcgis.com/ (last accessed 22 Jan 2020)

Forestry Commission (2018). Forestry Statistics 2018 - A compendium of statistics about woodland, forestry and primary wood processing in the United Kingdom, Forestry Commission.

Guiomar N, Godinho S, Pinto-Correia T, Almeida M, Bartolini F, Bezak P et al (2018) Typology and distribution of small farms in Europe: Towards a better picture. Land Use Policy 75:784-798

Graubner M (2018) Lost in space? The effect of direct payments on land rental prices. Eur Rev Agric Econ 45(2):143-171

Grunewald K, Schweppe-Kraft B, Syrbe RU, Meier S, Krüger T, Schorcht M, Walz U (2020) Hierarchical classification system of Germany's ecosystems as basis for an ecosystem accounting-methods and first results. One Ecosyst 5:e50648

Hanley N, Banerjee S, Lennox GD, Armsworth PR (2012) How should we incentivize private landowners to, produce' more biodiversity? Oxf Rev Econ Policy 28(1):93-113

Hein L, Bagstad KJ, Obst C, Edens B, Schenau S, Castillo G, Souland F, Brown C, Driver A, Bordt M, Steurer A, Harris R, Caparrós A (2020a) Global progress in the compilation of natural capital accounts for ecosystems. Science 367(6477):514-515

Hein L, Remme RP, Schenau S, Bogaart PW, Lof ME, Horlings E (2020b) Ecosystem accounting in the Netherlands. Ecosyst Serv 44:101118

Hein L, Bagstad K, Edens B, Obst C, de Jong R, Lesschen JP (2016) Defining ecosystem assets for natural capital accounting. PLoS ONE 11(11):0164460

Helm D (2019) Green and prosperous land: a blueprint for rescuing the British countryside. William Collins, Chichester

Hindle R, Thomson S, Skerratt S, McMorran R, Onea P (2014) Economic contribution of Estates in Scotland: an economic assessment for Scottish Land \& Estates. Scottish Government

Jones L, Vieno M, Morton D, Cryle P, Holland M, Carnell E, Nemitz E, Hall J, Beck R, Reis S, Pritchard N, Hayes F, Mills G, Koshy A, Dickie I (2017) Developing Estimates for the Valuation of Air Pollution Removal in Ecosystem Accounts. Final report UK Office of National Statistics

Kay S, Peuch J, Franco J (2015) Extent of farmland grabbing in the EU. Study requested by the European Parliament's Committee on Agriculture and Rural Development 
La Notte A, Maes J, Dalmazzone S, Crossman ND, Grizzetti B, Bidoglio G (2017) Physical and monetary ecosystem service accounts for Europe: A case study for in-stream nitrogen retention. Ecosyst Serv 23:18-29

La Notte A, Vallecillo S, Maes J (2019) Capacity as "virtual stock" in ecosystem services accounting. Ecol Ind 98:158-163

La Notte A, Marques A (2019) Adjusted macroeconomic indicators to account for ecosystem degradation: an illustrative example. Ecosyst Health Sustain 5(1):133-143

Lansing DM (2014) Unequal access to payments for ecosystem services: the case of Costa Rica. Dev Chang 45(6):1310-1331

Lawrence A, Dandy N (2014) Private landowners' approaches to planting and managing forests in the UK: what's the evidence? Land Use Policy 36:351-360

McDonald RI, Forman RTT, Kareiva P (2010) Open space loss and land inequality in United States' Cities, 1990-2000. PLoS ONE 5(3):e9509

Mace GM (2019) The ecology of natural capital accounting. Oxf Rev Econ Policy 35(1):54-67

Maes J, Teller A, Erhard M, Grizzetti B, Barredo JI, Paracchini ML, Condé S, Somma F, Orgiazzi A, Jones A, Zulian A, Vallecilo S, Petersen JE, Marquardt D, Kovacevic V, Abdul Malak D, Marin AI, Czúcz B, Mauri A, Loffler P, Bastrup- Birk A, Biala K, Christiansen T, Werner B (2018). Mapping and Assessment of Ecosystems and their Services. An analytical framework for mapping and assessment of ecosystem condition in EU. Discussion paper - Final January 2018. European Union

Mainar-Causapé AJ, Ferrari E, McDonald S (2018) Social Accounting Matrices: basic aspects and main steps for estimation. EUR 29297 EN, JRC Technical Reports. Publications Office of the European Union, Luxembourg, 2018

Mazzacuto M (2018) The value of everything: making and taking in the global economy. Allan Lane, London

McVittie A, Glenk K (2019) Natural capital accounts for Scotland: forest sector accounts, Scottish Government

McVittie A, Roberts M, Hopkins J, Glenk K (2019) Natural capital accounts for scotland: agriculture sector accounts. Scottish Government

Meya JN (2020) Environmental Inequality and Economic Valuation. Environ Resource Econ 76:235-270

Morton D, Rowland C, Wood C, Meek L, Marston C, Smith G, Simpson IC (2011) Final report for LCM2007 - the new UK land cover map. CS Technical report No. 11/07 NERC/Centre for Ecology and Hydrology $112 \mathrm{pp}$

Mullin K, Mitchell G, Rizwan Nawaz N, Waters RD (2018) Natural capital and the poor in England: towards an environmental justice analysis of ecosystem services in a high-income country. Landsc Urban Plan 176:10-21

Naidu S (2017) A Political Economy Take on W/Y. In: Boushey H, DeLong JD, Steinbaum M (eds) After Piketty: the agenda for economics and inequality. Harvard University Press, Cambridge

Nature Scot (2021) Piloting an Outcomes Based Approach in Scotland (POBAS) project. Project webpage infromation. Available online: https://www.nature.scot/doc/piloting-outcomes-based-appro ach-scotland-pobas-project Last accessed [23 May 2021]

NCC (Natural Capital Committee) (2020) State of Natural Capital: Annual Report 2020, NCC, London

Nemitz E, Vieno M, Carnell E, Fitch A, Steadman C, Cryle P, Jones L (2020) Potential and limitation of air pollution mitigation by vegetation and uncertainties of deposition-based evaluations: Air pollution mitigation by vegetation. Philos Trans R Soc 378:0190320

NRS (National Records of Scotland), 2016. Scottish Settlement boundaries version (released March 2018)

Obst C, Hein L, Edens B (2016) National accounting and the valuation of ecosystem assets and their services. Environ Resource Econ 64(1):1-23

Obst C, Vardon M (2014) Recording environmental assets in the national accounts. Oxf Rev Econ Policy 30:126-144

OECD (2015), Public goods and externalities: agri-environmental policy measures in selected OECD Countries, OECD Publishing, Paris

ONS (2020a) Scottish Natural Capital Accounts: 2020, UK Office for National Statistics

ONS (2020b) Population Estimates for the UK, England and Wales, Scotland and Northern Ireland: mid-2018, UK Office for National Statistics

ONS (2019) UK Natural Capital Accounts: 2019, UK Office for National Statistic

ONS (2018) UK air pollution removal: how much pollution does vegetation remove in your area? UK Office for National Statistics Available online: https://www.ons.gov.uk/ (last accessed 23 Jan 18) 
Ovando P, Caparrós A, Diaz-Balteiro L, Pasalodos M, Beguería S, Oviedo JL, Montero G, Campos P (2017) Spatial valuation of forests' environmental assets: an application to Andalusian Silvopastoral farms. Land Econ 93(1):87-108

Pannell DJ (2008) Public benefits, private benefits, and policy mechanism choice for land-use change for environmental benefits. Land Econ 84(2):225-240

Pašakarnis G, Maliene V (2010) Towards sustainable rural development in Central and Eastern Europe: Applying land consolidation. Land Use Policy 27(2):545-549

Pascual U, Phelps J, Garmendia E, Brown K, Corbera E, Martin A, Gomez-Baggethun E, Muradian R (2014) Social equity matters in payments for ecosystem services. Bioscience 64(11):1027-1036

Piketty T, Saez E, Zucman G (2018) Distributional national accounts: methods and estimates for the United States. Quart J Econ 133(2):553-609

Riley CB, Gardiner MM (2020) Examining the distributional equity of urban tree canopy cover and ecosystem services across United States cities. PLoS ONE 15(2):e0228499

Salhofer K, Feichtinger P (2020) Regional differences in the capitalisation of first and second pillar payments of the CAP into land rental prices. Eur Rev Agric Econ 48(1):8-41

Scottish Government (2020a) June Agricultural Census 2020 Available online: (https://www.gov.scot/ publications/scottish-agricultural-census-final-results-june-2020/) last accessed 27 May 2021

Scottish Government (2020b) Banded income Statistics: 2015 Available online: (https://www.gov.scot/ publications/banded-income-statistics-2015/ / ) last accessed 13 Aug 2020

Scottish Government (2019). FCS National Forest Estate (WMS). Available online (https://data.gov.uk/ dataset/44dcf360-3af9-407c-8d1e-5d2a8b5a3a2b/fcs-national-forest-estate-wms) last accessed 21 Jan 2020

Scottish Government (2016) Economic Report on Scottish Agriculture 2016 Edition. Structure of the agricultural farms in Scotland. Available online: (https://www.gov.scot/publications/economic-report-scott ish-agriculture-2016/) last accessed 12 Apr 2021

Shrubsole, G. (2019) Who Owns England?: How We Lost Our Green and Pleasant Land, and How to Take It Back, William Collins, 384 pp

Teytelboym A (2019) Natural capital market design. Oxf Rev Econ Policy 35(1):138-161

UN (2021) System of environmental-economic accounting - ecosystem, accounting. final draft. United Nations, SEEA. Available online: (https://seea.un.org/ecosystem-accounting). last accessed 13 Apr 2020

UN (2018) Handbook on supply and use tables and input-output tables with extensions and applications, United Nations, New York

UN (2009) System of National Accounts 2008, United Nations, New York

Vallecillo S, La Notte A, Ferrini S, Maes J (2019) How ecosystem services are changing: an accounting application at the EU level. Ecosyst Serv 40:101044

Van den Ven P, Edens B, Obst C (2019) Accounting treatments when integrating ecosystem accounts in the SNA, Discussion Paper 5.3, Working Group 5: Valuation and accounting treatments, UNSD/ SEEA, New York

Varacca A, Guastella G, Pareglio S, Sckokai P (2021) A meta-analysis of the capitalisation of CAP direct payments into land prices. Eur Rev Agric Econ. https://doi.org/10.1093/erae/jbab014

Vincent JR (2015) Valuing Environmental Services in the SNA, Report prepared for the Policy and Technical Experts Committee (PTEC) of the Wealth Accounting and Valuation of Ecosystem Services (WAVES), The World Bank, Washington D.C.

Walker G (2012) Environmental justice: concepts evidence and politics. Routledge, London

Wightman A (1996) Who Owns Scotland? Canongate, Edinburgh

Who Owns Scotland (2015) property map. Last update (2015). Online resource: http://www.whoownssco tland.org.uk/index.php (last accessed 29 Oct 2020)

Publisher's Note Springer Nature remains neutral with regard to jurisdictional claims in published maps and institutional affiliations. 